\title{
THE EMPLOYMENT OF ZEUGMA AND SYLLEPSIS IN ADAGES AND FAMOUS QUOTES AS A KIND OF DISCOURSE GENERA May Tahseen Hameed $^{1 *}$, Hind Tahseen Hameed ${ }^{2}$ \\ ${ }^{1 * 2}$ English Department, College of Education for Human Sciences, Diyala University, Iraq. Email: "maytahseen14@gmail.com
}

Article History: Received on $29^{\text {th }}$ July 2021, Revised on $10^{\text {th }}$ August 2021, Published on $15^{\text {th }}$ August 2021

\begin{abstract}
Purpose of the study: The study aims to explore zeugma and syllepsis in adages and famous quotes as discourse forms. This study also aims to determine if they are different figures of speech, if they are widely used in adages, famous quotes in literature, why they are employed in the text's message, and which type among their subtypes is most important prominent.
\end{abstract}

Methodology: The study follows the major categories of zeugma and Seagal's model of syllepsis. This research is of theoretical type, and the research method is descriptive-analytical. The data collection method is a library and refers to documents, books, and articles.

Results: The findings of this study indicated that they are widely used in this type of discourse, prozeugma is most prominent, and that they are different figures, while syllepsis is rare.

Application: These results will enhance the writerlspeaker's appreciation ability and language performance by using the figure of speech as a tool in their message.

Novelty: The results of this study should be reliable in the field of discourse analysis when speakers $\backslash$ writers want to deliver an effective and strong language.

Keywords: Zeugma, Syllepsis, Figures of Speech, Adages, Quotes.

\section{INTRODUCTION}

In order to create a persuasive message, speakers and writers have to put eupraxia sentences at their service (Fahnestock, 2011) and speed a text up either a written or a spoken one, and confirm the combined content there arouse heed in rhetorical stylistic. They may use zeugma or syllepsis as chains of sequences to reach this aim; in zeugma, some subjects or objects share one verb; and they use a verb with two senses and two objects it plays with meaning. So, one can say they are a kind of abbreviation of language when one wants to use words economically, and one uses them also for conciseness and other impacts; instead of saying "walking up and walking down," we can say "walking up and down."

Zeugma is a figure of speech in which a word is used to modify or govern two or more words, although appropriate to only one or making a diverse sense with each. In comparison, syllepsis is a figure of speech when a grammatical construction in which a single word is used to modify or govern two or more words in the same sentence syntactically. However, it can grammatically fit with only one. Zeugma and syllepsis appear in coordinate sentences with (and, or, nor, and but) Ex. John loves Mary, but Harry Jane (Rooryck, 1985), in the same book Marouzeau distinguishes three types of zeugma in his definition according to the place of the verb (Rooryck,1985, p. 203). Zeugma comes from the Greek meaning "yoking" or "bonding" Ex. John lost his coat and his temper. "Lost" applied to the nouns "coat" and "temper," "losing coat and losing temper" are logically and grammatically different ideas but were joined in this sentence. So being a figure of speech in which two terms are joined together inappropriately, this is how Lascarides (1996: p, 2) defines it; it is a word shared between clauses in spite of having different senses in each context. Another example of zeugma is Cruse's (1986, p. 63):

Ex. Arthur and his driver's license expired on Tuesday.

The verb expire has two evident but associable senses "i. e., died and no longer valid." On the grammatical level, zeugma is a deletion of syntactic units in favor of meaning, one used to consummate the meaning of two or more adjoining words or clauses. It can be seen as "a single supply" for by a single word, we ministering many clauses. In this case, the structure contains a specific syntactic category, a verb or adjective, which ministering at least two other syntactic categories may be nouns according to Shen (2002); therefore, zeugma is used in a poetic way prescribed by the context of use. Here we are talking about the semantic use of the word.

Quinn (1982), in his book, sees zeugma as "Ellipsis of the verb from one of two or more usually parallel clauses," and syllepsis as "A combination of ellipsis and antanaclasis." Some linguists call the phenomenon of zeugma "gapping," among them (Rooryck, 1985), it is a kind of reduction in the use of language. The gap should have the verb that the coupled elements belong to the same functional and semantic class. In some cases, gapping is a must and not only a simple stylistic operation.

There are two ways in which zeugma can be presented: first, the more salient element comes first, the second is the less salient one later. 
"He packed his shirt and sadness '(first type)

"He packed his sadness and shirt "(second type).

This means the literally used noun is more salient than the metaphorical one, considering the shared prediction as stated by Gibbs (2008). So, the order of the words in the sentence and when the sense of the verb varies for the following noun the standard order for nouns: the first noun taking the less prototypical or figurative verb meaning.

"The boy Swallowed milk and kisses vs. The boy swallowed kisses and milk."

As Seagal (2015) mentions, the meaning is clear, and nobody would choose the error; he may take spare time and a strong vision. When the verb is applied with unequal meaning to the governed clauses, we get a purely formed pattern of zeugma (Katz, 1998; Gibbs, 2008).

Syllepsis occurs when a word figures in a structure with two clauses, but it is fitted with only one of them or added to them in different senses; one is literal, the other metaphorical. Both zeugma and syllepsis are pun (Norrick, 1981). Syllepsis employs the technique of using a verb for more than one part in a sentence but where that single verb applies grammatically and logically to only one:

Ex. They saw lots of thunder and lighting.

The verb "saw" is logically correct only for the lighting, as thunder is "heard" Seagal (2015) mentions, "It lacks grammatical correctness, "according to ancient grammarians, it is a figure of syntax. It is often considered a kind of zeugma because some linguists see zeugma as controlling both semantic and grammatical scenarios. Zeugma and syllepsis are very confusing; even linguists try not to split them, sometimes it is difficult to recognize which is which for they are confusing and contradictory but rather different. Many modern linguists, among them Warren (1999), stated in his research comparing between them; they are distinct constructions arising from two cognitive operations.

In his work, Quinn (1982) says that the sense or semantic relation between the adjacent words in the context is literal on one side and transferred or metaphorical on the other, so one is concrete the other is abstract, there is a clash between the two meanings, they are an effective device pertains the purity of the primary meaning. Short (2017) sees it as a kind of metaphor. Croft (2004) describes zeugma and syllepsis as a case when two readings are simultaneously evoked in connection with a single occurrence of a word. Syllepsis is considered a "double supply," a figure omitting words while making others serve several needs. According to Sloane (2001), there is an admixed in rhetorical treaties between syllepsis and zeugma in the limits of elliptical word. Both of them include artful changes in the actual composition of language (Shen, 2002).

This study tries to figure out why these figures are used in adages and famous quotes, the importance of using them, what they can apply to texts, and which type is most used and why. This will help to make more effective and brilliant language by making use of these figures. The study also tries to fill in the gap in this side of the discourse. There is no study concerning zeugma and syllepsis as distinct figures of speech on the one hand, and analyzing them in adages and famous quotes as widely used and reliable in everyday speech and literature.

\section{METHODOLOGY}

This research is of theoretical type, and the research method is descriptive-analytical. The data collection method is the library and has been done by referring to documents, books, and articles.

\section{RESULTS AND DISCUSSION}

\section{The Usages of Zeugma and Syllepsis}

Zeugma is a tool to generate different senses; according to Du-Mo (2006), it is of four mechanisms for the usage:

A) One verb +two or more objects

Ex. Kill the lady and the luggage.

B) Preposition+ two or more objects

Ex. Went straight home, in the flood of tears, and sadden chair.

C) Two subjects +one verb.

Ex. Ten minutes later, the coffee and commander Dana of naval intelligence arrived simultaneously.

D) Adjective +two or more nouns or noun phrases or noun phrases

Ex. She is having a blue coat and a heart today.

The way syllepsis work is by making two connotations, but the keyword is correctly added or fitting with both of them in grammar and syntax. So, it uses any part of speech in connection to two other words or phrases, in a correct way 
regarding every one separately, as to both syntax and sense, but in different ways to produce a witty effect (Du-Mo, 2006).

Ex. The newly chosen boss of the committee (took) the (oath) and (his seat).

\section{The Importance of Context}

Zeugma is created by omitting the second and third instances of the same word. Omitting words can still be understood by the context of the remaining words. Linguists do not require that the governing word always be a verb. Context plays a crucial role in determining the meaning of the intended sentence and what the individual words within this sentence are referring to. Zeugma and syllepsis can be fairly pleasing as they rely on the reader to understand a definite word's various shades of meaning.

In several diverse ways, the context of the words of use illuminates and limits their meanings. The linguistic and pragmatic context specifies the characteristics of the word; Kroeger (2018) explains that the context makes it obvious which of the senses is intended when the lexically hazy word is used. The speaker asks the hearer to has the ability to choose the single intended senses relying on context. This context makes zeugma and syllepsis function as figures of speech. Kroeger (2018) mentions that this context of utterance habitually signals out ...the one sense which is planned from amongst the various senses of which the word is potentially capable; the interpreter is simply fudging the exegesis. Sometimes and in certain contexts, the sentences are regarded as ungrammatical because grammar rules are twisted by necessity or for stylistic purposes, like when incompatible objects are yoked with one verb and used in different meanings for each object.

Another example is when poetic zeugma appears in a non-systematic order of presentation; what determined its order is the exact context, either a specific poem, a period, etc. and not any other broad principle. Both stylistic devices acquire some extra contextual meaning; the words start to leave their primary senses and get contextual ones and give different senses in each context. The hearerlreader must supply the omitted items without the direct textual help which is provided in other varieties.

\section{The Differences between Zeugma and Syllepsis}

The difference between zeugma and syllepsis is slight, and rhetoricians have struggled to categorize them efficiently as below:

1- Syllepsis conserves the literal meaning of the words but organize the deviously; zeugma transforms the concrete meaning or the original of the word or phrase;

2- Emphasis differences: if the verb is at the end zeugma permits a concise or even poetic statement of the situation, syllepsis emphasizes inappropriateness between the meaning of a verb or different field of sense nouns.

3- Zeugma serves as a device to adjust or rule two or more words in the same sentence but applying in a sense to only one of them or applying in a sense to them in dissimilar senses. The same is true of syllepsis, but in contrast to zeugma, it need not have either of these tasks, and the keywords can be repeated but served in diverse meanings in the same sentence.

4- Constructional aspect: zeugma is basically a syntagmatic construction, more precisely one of the amalgamations in which the collocation is implicit by grammar, whereas syllepsis is basically a property -transporting semantic procedure.

5- Settings on meaning transfer and psychology meaning transfer are possible when there is an apparent connection between the properties of one thing and that of another; sometimes, there is a straight functional relation between two sets of properties as in cases of zeugma, which is in contrast to syllepsis.

6- In syllepsis, if both expressions in separate sentences have to alter senses within the same sentence completely, both would be absolutely accurate. The effect of syllepsis is often humorous; the hasty change of sense seems to appeal to whatever sense realizes double meanings and to humor, satire, and any writing in a light ironic tone. Zeugma is sometimes considered an error.

7- Zeugma implies ellipsis, but syllepsis doesn’t have to imply ellipsis.

8- Intentional or not intentional; zeugma is not clear whether intentional or not may cause ambiguity in understanding what the writer's intention, but a fine writer would distinguish the zeugma, decide which meaning he wants, and then express the idea in a novel, unambiguous sentence (Du-Mo, 2006).

\section{Why using Zeugma and Syllepsis}

Both are a piece of language (normally more than a single word) that has an abnormal arrangement. It intends to alter the shape of language, seeking to create a more expressive and humorous language that can be effortlessly understood, so they are figures of speech. They involve crafty changes in the real structure of language. Using them will offer cognitive insights into the working of expressing ideas concisely and powerful (zeugma) while, at the same time, permitting and 
encouraging us to look for furors and zany ways in which the same term can be used (syllepsis) (Kroeger, 2018). They also can express a rich language significance to generate a kind of a pun, used with comic or satiric effect. As a constituent of persuasive speech, they help draw special awareness to language or appeal to an audience's emotions; they play a fundamentally argumentative role in discourse by inducing conceptual relationships and imposing a particular structure on these relationships. As urged by Fahnestock (2011) and Short (2017), they facilitate persuasion in these ways by widening the use of a verb and creating figurative use.

They are a kind of playing on words, for they give the sentence comedic and dramatic effect. It needs the comedic effect that comes from the astonishing and clever sentence construction. They memorably drove a point; they are so pithy that they make the speaker come off as sharp and spontaneous, mainly when spoken aloud. They are fun to read becau se they are pleasant and smart. They stick in mind and make an idea stick in the reader's imagination simply and to inspire deeper thinking or to create a shock. They retain the purity of the primary meaning when both meanings clash. Each of them stands out clearly, making the literary works more interesting, giving beauty, variety, coherence, and force to a composition (Croft, 2004).

\section{Categories of Zeugma}

The analysis in this paper is guided by the main categories of Zeugma set by linguists. The following are those of zeugma figures which are of two types: those categorized according to the position of the governing verb and those on which the governing word is another part of speech (usually the subject noun) (Foreyth, 2004):

A) Zeugma figures related to the specific type and location of the governing verb;

1-Hypozeugma (or adjunctions) is used in a construction containing several phrases and occurs when the word or words on which all the phrases depend are placed at the end, after the governed parts.

Ex. "His clothes, his books, and his dignity were lost."

2- Prozeugma or synezeugma is a zeugma whose governing words occurs in the first clause of the sentence before the governed parts,

Ex. "He took his hat, and his vacation."

3- Mesozeugma (conjunction): The governing word occurs in the middle of (between) the sentence and minister clauses on each side;

Ex. "He worked nights, I days."

B) A governing noun:

1- Diazeugma: Only subject ministers numerous verbs.

C) A diazeugma whose only subject begins the sentence and controls a series of verbs is a "disjunction." Ex. "John receives the ball dribbles, dodges the defender, shoots, and scores."

D) A diazeugma conjunction where the subject is in the middle of the sentence,

Ex. "Afraid and unhappy, the boy stood alone in the world."

\section{Types of Syllepsis}

The analysis depends on Seagal's (2015) model in classifying syllepsis. His division is similar in many points to other linguists' but is more overwhelming and detailed; his works are as follows:

1) A noun phrase syllepsis: A single predicate added to two or more parts of a sentence but lacks grammatical precision (Lascarides, 1996), one form of the main verb joins, ungrammatically, with different noun phrases or auxiliary verbs (Broun and Miller, 2013). According to this, the verb follows the first noun phrase, Ex. "He works, I mine "; in this example, the subject is not disjunctive, and the verb follows the first noun phrase that is its subject but precedes the second involves a disjunctive subject: in this case, the verb either follows both noun phrases or precedes both of them. (Seagal, 2015) mentions that this kind obtains the most grammatical safety.

2) Auxiliary syllepsis: A single form of a verb, either the main verb or an auxiliary, combines with more than one auxiliary verb.

Ex. "She has deceived her father and may thee"

3) (Seagal, 2015) names a third type Syllepsis "free equivalent "when a single auxiliary verb (did) combined with two different main verbs,

Ex. Nor ever did he speak nor look at me.

The Corpus Data 
A sample of (797) adages and famous quotes were collected, analyzed, and scheduled. The quotes are taken from interviews or speeches of well-known writers, actors, singers, presidents, leaders, etc. picturing a wise saying or a summary of a life experience or a description of some feeling, so they came to be used as an aphorism or taken from a work of art like a novel or a movie. They are never out of context of utterance because they were said within a specific one; this is also true of adages because speakers put them according to the context of speaking in agreement with how they tend to use them in their speech.

\section{The Analysis}

Because of the limitation in time and space, a few examples were chosen to demonstrate the analysis leading to the study's final results. Below are samples from the corpus data:

Sentence (1) "Eggs and oaths soon broken."

This is a (hypozeugma): a single verb at the end of a succession of clauses to modify the entire series. Broken fits (egg) literally and used with (oaths) figuratively, there is a disparity in the way that parallel members related to the governing word (as a vice or for a comic effect). The verb is used in two different senses; two nouns with one verb make the sentence tense, tightly knit, vivid, fun, novel, and has a special expressivity, and by using (broken) with (oaths) changes the verb's initial meaning. The structure of the sentence is one verb +two objects.

Sentence (2)" Give neither counsel nor salt till you are asked for it."

The use of correlative conjunctions (neither \ nor, either \or, and not \only \but also) often creates zeugma. In this sentence, it is a (prozeugma), (give) is suitable with (salt) not with (counsel), it is one verb +two objects.

Sentence (3)" The storm sank my boat and my dreams."

This is a (prozeugma); it is used here to make the feeling of sadness over the loss of a treasured boat and a long life plan more pronounced than something literal like "My boat sank in the storm. I couldn't realize my dreams." When the literary element first in the sentence will usually read better. Each prozeugma carries the mechanism (one verb, +two objects).

Sentence (4) "The levees were broken and so were the promises."

This famous quote said by Anderson Cooper using (mesozeugma), the verb (broken) joins the two parts of the sentence it is used literarily with (levees) and metaphorically with (promises). Mesozeugma takes the structure (two subjects + one verb).

Sentence (5) "Nor God, nor I, delights in perjur'd men” (Shakespeare, 2009)

This is a Shakespearian quote that uses the verb (delights) with both (God) and(I) while it is correct only with (God), it is a noun phrase syllepsis where the verb follows the first noun phrase and precedes the second one.

Sentence (6) "Standing accused, threatening our homes, reveling in his crime, this man guilty of burglary asks our forgiveness."

(This man) is a diazeugma conjunction, the subject joins the two clauses together and is the same for each, and the structure is (one subject governing two more verbs).

Sentence (7) "Physical beauty: with disease it fades; with age it dies."

Diazeugma disjunction: (physical beauty) is the subject for both clauses, and the reader should apply it because it is omitted it comes in the form (one subject +two verbs) always diaguzema takes this structure.

Sentence (8) "Yes, my teeth and ambitions are bared."

This quote was said by Scar in "Lion King," it is a (hypozeugma) the same as this quote from Sherry "Hours, days, weeks, months, and years do pass away." The mechanism, of course, is (one verb +two subjects) because it is a hypozeugma.

Sentence (9) "Histories make men wise; poets, witty; the mathematics subtle; natural philosophy, deep; moral, grave; logic and rhetoric, able to contend." (Bacon, 2009)

This is a (prozeugma) where the verb(make) at the very beginning of the sentence is omitted in the rest but should be applied in the reader's mind. The verb is governing more than two objects.

Sentence (10) "You are free to execute your laws, and your citizens, as you see fit." (Riker, "Star Trek: The Next Generation")

The verb (execute) applies to (laws) and (citizens); as a result, it gives a shocking effect. It is a (prozeugma) of the kind one verb +two objects. 
Sentence (11) "And all the people saw the thundering, and the lighting, and the noise of the trumpet, and the mountain smoking: and stood afar off." (The Holy Bible (n.d.))

The verb (saw) is used to refer to (the thundering), (the lighting), and (the noise); people can only see the lighting but can't see noise or thunder. It is a mesozeugma.

Sentence (12) "Now when all the clowns that have commissioned have died in battle or in vain." (Dylan, 1965)

It is a mesozeugma (died) that connects the parts of the sentence and is used to (be died in battle or to be died in vain), which is figurative (one verb +two objects).

Sentence (13) "There are two ways of spreading light: to be the candle or the mirror that reflects it." (Edith Wharton Quotes (n.d.))

A mesozeugma, the original sentence is (There are two ways of spreading light: to be the candle or to be the mirror that reflects it.)

Sentence (14) "If you want to live a happy life, tie it to a goal, not to people or things." (Albert Einstein Quotes (n.d.))

A (mesozeugma) tie is used literally with people or things and figuratively with (goals). This sparkles the hearer's imagination; here, zeugma is used as (one verb +tow objects).

Sentence (15) "It matters not what someone is born, but what they grow to be." (Rowling, J.K., Harry Potter and the Goblet of Fire)

Here we have a case where there are two situations (matters) is used in the first clause but is omitted in the second (...but it matters what they grow to be), the verb precedes the noun phrases, then a second case (someone is born) then (they grow), someone is singular takes the verb(is) and in the second comes (they) and the verb (grow) not in a singular form, in accordance with (someone is). It is a noun phrase syllepsis.

The final results of the analysis of zeugma are in (Table 1) which shows the frequency of each category and their percentage:

Table 1: Frequency and percentage of zeugma categories

\begin{tabular}{lll}
\hline Zeugma Category & Frequency & Percentage \\
\hline Prozeuma & 201 & $33.8 \%$ \\
\hline Hypozeugma & 69 & $11.6 \%$ \\
\hline Mesozeugma & 106 & $17.8 \%$ \\
\hline Diazeugma Disjunction & 139 & $23.4 \%$ \\
\hline Diazeugma Conjunction & 80 & $13.4 \%$ \\
\hline Total & 595 & $100 \%$ \\
\hline
\end{tabular}

Source: Authors

The following (Table 2) concerning the results of syllepsis:

Table 2: Frequency and percentage of types of syllepsis

\begin{tabular}{lll}
\hline Types & Frequency & Percentage \\
\hline Noun Phrase & 85 & $42.1 \%$ \\
\hline auxiliary & 62 & $30.7 \%$ \\
\hline Did +two different main verbs & 55 & $27.2 \%$ \\
\hline Total & 202 & $100 \%$ \\
\hline
\end{tabular}

\section{Source: Authors}

Out of 797 adages and famous quotes, zeugma appeared 595 times, and prozeugma was the most prominent amongst the other categories, while syllepsis appeared 202 times; noun phrase is the most frequently used type (Table 3).

Table 3: The total frequencies and percentage of zeugma and syllepsis

\begin{tabular}{lll}
\hline Kind & Frequency & Percentage \\
\hline Zeugma & 595 & $74.6 \%$ \\
\hline Syllepsis & 202 & $25.4 \%$ \\
\hline Total & 797 & $100 \%$ \\
\hline
\end{tabular}

Source: Author

From the analysis of the data, the results showed that the most used kind is zeugma, it appeared 595 times this means that speaker $\backslash$ hearer uses it a lot in adages and quotes to add a special appeal to their language the results also showed 
that the total percentage of zeugma was 74. 6\%. Among the categories of zeugma (prozeugma) appeared 201 times and with a percentage of 33. $8 \%$, while (diazeugma disjunction) appeared for 139 times, and (diazeugma conjunction) for 80 times with a percentage of $23.4 \%$, and $13.4 \%$ respectively, then came mesozeugma for 106 times, with a percentage of 17. $8 \%$ while (hypozeugma) appeared 69 times, with a percentage of $11.6 \%$. After zeugma came syllepsis appearing 202 times, with a percentage of $25.4 \%$ divided among noun phrase syllepsis with a frequency of 85 times and with a percentage of $42.1 \%$; auxiliary syllepsis, which appeared 62 times, with a percentage of $30.7 \%$, and in the last place was (did) with two different main verbs appearing 55 times with a percentage of $27.2 \%$.

\section{CONCLUSION}

Zeugma and syllepsis are figures of speech; they are a piece of language that has an unusual arrangement; their purpose is to change the shape of language aiming at creating a more expressive and humorous one, which can be easily understood, they involve artful changes in the actual structure of language. Zeugma and syllepsis are two distinct constructions arising from two distinct cognitive operations. However, they are alike in that they both involve an explicit source expression which suggests an implicit target; the difference between them is slight, and rhetoricians have struggled to categorize them effectively. The emphasis of the study was on whether they are used in adages and famous quotes being a kind of discourse genera and on whether there is a specific category that is most prominent. Analyzing the data leads to the conclusion that people use zeugma, especially prozeugma, because in placing the zeugmatic element at the beginning, one draws attention and emphasis to the dominating element to control the rest of the discourse and that people use figurative language with zeugma and syllepsis to create effective sentences and to add vividness, life, coherence, humor, and wittiness to discourse. The rarely used kind is (did +two verbs syllepsis) because it has the weakest influence added to the structure of the sentence compared to the other kinds. When the governing word is applied to two or more modified words in a novel way, it makes the reader $\backslash$ hearer pause -maybe because he is unsure of having read $\backslash$ hear the sentence correctly, or he wants to stay behind a skillful play with language, this ability to create a pause or breathing space within a text makes zeugma a powerful device.

\section{SUGGESTION}

In comparison with the categories of zeugma, syllepsis is not often to be used. When using zeugma skillfully, one will produce a unique artistic effect in making the sentence function to serve to adorn expressions adding emphasis to ideas in an impressive style. The sentence will be more fun, and the zeugma in it will create a sense of drama. The structure of syllepsis is more complicated in use than the structure of zeugma, so people tend to use zeugma more, which also confirms whether adages and famous quotes deeply rely on these figures of speech in creating effective sentences.

\section{LIMITATION AND STUDY FORWARD}

The study's restrictions are that it didn't collect all the adages or famous quotes in the language; it took a large number of them and tried to study them following a specific linguistic model. Other studies can analyze zeugma and syllepsis according to other linguistic models.

\section{AUTHORS CONTRIBUTION}

The main and principal author worked on the idea, methodology, concept, data collection, analysis, revision, and study improvement. Both authors did the statistical analysis and the study's findings.

\section{REFERENCES}

1. Albert Einstein Quotes(n.d.). Goodreads.com. Retrieved from https://www.goodreads.com/quotes/141245-ifyou-want-to-live-a-happy-life-tie-it

2. Bacon, F. (2009). The Collected Works of Sir Francis Bacon. Halcyon Press Ltd.

3. Broun, K. and Miller, J. (2013). The Cambridge Dictionary of Linguistics. Cambridge University Press. https://doi.org/10.1017/(CBO9781139049412

4. Croft, W. (2004). Cognitive Linguistics. New York: Cambridge University Press, pp. 245-169. https://doi.org/10.1017//CB09780511803864

5. Cruse, D. (1986). Lexical semantic relations. Cambridge, England: Cambridge University Press.

6. Du-Mo, J. (2006). The Difference between Zeugma and syllepsis. US-China Foreign Language, 4(11), 28-31.

7. Dylan, B. (1965). Queen Jane Approximately. Retrieved from https://www.bobdylan.com/songs/queen-janeapproximately/

8. Edith Wharton Quotes. (n.d.). BrainyQuote.com. Retrieved from https://www.brainyquote.com/quotes/edith wharton 100511

9. Fahnestock, J. (2011). Rhetorical Style: The Uses of Language in Persuasion, New York: Oxford University Press, PP: 174-183.

10. Foreyth, M. (2004). The Elements of Eloquence, New York: Penguin, PP: 110-111

11. Gibbs, J. (2008). The Cambridge Hand Book of Metaphor and Thought, New York: Cambridge University Press, PP: 300-312.

12. Katz, A. (1998). Language and Thought. New York: Oxford University Press, PP: 88-94.

13. Kroeger, P. (2018). An Introduction to Semantics and Pragmatics. Berlin: Language Science Press, PP: 33-40. 
14. Lascarides, A. (1996). Ambiguity and Coherence, Journal of Semantics, 13(1), 41-65.

15. Norrick, N. (1981). Semiotic Principles in Semantic Theory, Amsterdam: John Benjamins, PP: 44-60.

16. Quinn, A. (1982). Figure of Speech 60 Ways to Turn a Phrase. Salt Lake City: A Peregrine Smith Book.

17. Rooryck, J. (1985). Gapping -Zeugma in French and English: a non Deletion Analysis. Linguistic Analysis, $15(2-3), 187-213$.

18. Seagal, A. (2015). Syllepsis: An Unfought Wars. Advances in Language and Battle. Language Studies, 6(2), 137-147.

19. Shakespeare, W. (2009). Love's Labour's Lost (The New Cambridge Shakespeare) (W. Carroll, Ed.). Cambridge: Cambridge University Press. https://doi.org/10.1017/9781139836517

20. Shen, Y. (2002). Cognitive Constructions on Verbal Creativity: the Use of Figurative Language in Poetic Discourse. In E Semin J. Culpeper (eds.), Amirce: John Benjamins, PP: 60-74.

21. Short, W. (2017). Can Figures of Speech Persuade? An Argument from Zeugma. In Liao, T. \& Vatr, a. (eds.). The Language of Persuasion. Linguistic Approaches to its Theory and Practice in the Classical and Practice in the Classical World. Amsterdam: Studies in the Classical Philology. Leiden: Brill, PP: 12-27.

22. Sloane, T. (2001). Encyclopedia of Rhetoric. Oxford: Oxford University, PP: 788-796.

23. The Holy Bible (n.d.). Authorised King James Version (Printed by Authority). World Publishing.

24. Warren, B. (1999). Aspects of Referential Metonomy. In Panther, K. U. \& Radden, G. (eds.), Metonymy in Language and Thought. Amsterdam: John Benjamins, PP: 124-133. 